University of Louisville

ThinkIR: The University of Louisville's Institutional Repository

Electronic Theses and Dissertations

$5-2021$

\title{
Love labor: literal symbols and true abstractions.
}

\author{
Karen Weeks \\ University of Louisville
}

Follow this and additional works at: https://ir.library.louisville.edu/etd

Part of the Art Practice Commons, and the Fine Arts Commons

\section{Recommended Citation}

Weeks, Karen, "Love labor: literal symbols and true abstractions." (2021). Electronic Theses and Dissertations. Paper 3627.

https://doi.org/10.18297/etd/3627

This Master's Thesis is brought to you for free and open access by ThinkIR: The University of Louisville's Institutional Repository. It has been accepted for inclusion in Electronic Theses and Dissertations by an authorized administrator of ThinkIR: The University of Louisville's Institutional Repository. This title appears here courtesy of the author, who has retained all other copyrights. For more information, please contact thinkir@louisville.edu. 
LOVE LABOR: LITERAL SYMBOLS AND TRUE ABSTRACTIONS

\author{
By \\ Karen Weeks \\ B.F.A., Indiana University, 2006
}

\begin{abstract}
A Thesis
Submitted to the Faculty of the

College of Arts and Sciences of the University of Louisville

In Partial Fulfillment of the Requirements

For the Degree of
\end{abstract}

\author{
Master of Fine Arts \\ in Studio Art and Design
}

Hite Art Institute

University of Louisville

Louisville, Kentucky

May 2021 
Copyright 2021 by Karen Weeks

All rights reserved 

LOVE LABORS: LITERAL SYMBOLS AND TRUE ABSTRACTIONS

\author{
By \\ Karen Weeks \\ B.F.A., Indiana University, 2006 \\ A Thesis Approved on
}

April 12, 2021

by the following Thesis Committee:

Thesis Director
Rachel Singel M.F.A.

Rachel Singel M.F.A.

Second Committee Member

John Gibson PhD

Third Committee Member

Benjamin Hufbauer PhD 


\section{DEDICATION}

This thesis is dedicated to Eleanor and Johannes Sabo for making me a mama, and giving me the gift of perspective and love, with which I made this work.

To Jeff Nilan whose constant, unwavering love and support has inspired me, shored me up and given me courage.

To Amos Paul Kennedy Jr, for tasking me to Proceed and be Bold, and for his endless encouragement, belief and interest in what I have to say and create. To Roy P. Germano III for our longtime friendship and trust, and most recently, our musings about professional development.

To Rachel Brewer, Stacy Kirkman, Anja Hänsch, Susanne Pauli, Sanjukta Maitra, and Shana Berger who have stayed with me, and have fed me with their stories, intellect, humor and profound points of view. 


\section{ACKNOWLEDGEMENTS}

I would like to acknowledge the Hite Art Institute and my mentor in the MFA program, Rachel Singel, for her kindness and support. I would like to thank Professor Lizzie Gulick, Professor Katie Ovechkin, Professor Mary Carothers, Professor Chris Reitz, Professor John Gibson and Professor Benjamin Hufbauer, all of whom were instrumental in the realization of this thesis work. Thank you for your teaching excellence, sharing of knowledge, expertise, and guidance. I would like to thank the women who donated their knitting projects to me so that I could make some of this work and lastly, I would like to thank Thomas Michael Sabo, $\mathrm{PhD}$ for our travels together through the mess of parenting and becoming. 


\section{ABSTRACT \\ LOVE LABOR: LITERAL SYMBOLS \& TRUE ABSTRACTIONS Karen Weeks}

April 21, 2021

If the home can be a metaphor for our own interiors, then the things that collect there can be similarly thought of, performing as punctuated moments within that interior, giving it shape, creating contours. Within the domestic setting, macro social forces such as global capitalism as well as the more immediate experience of meeting our children's demands can push and pull us, equally informing the experience of being in the home. Love Labor: Literal Symbols and True Abstractions is comprised of images sourced from common ephemera of the home meant to represent the everyday: notes, discarded letters, open envelopes, unfinished knitting, garments, drawings, math homework. The works in this show seek to reimage this detritus by (re)organizing it into constructed passages that bear witness to the commonalities to be found in homemaking and artmaking, aesthetics and the commonplace, economics and whining. They are abstract representations of that which is contained within us, as they are in our homes, seeking to explore the aesthetics of and the profundities contained within the mundane. 


\section{TABLE OF CONTENTS}

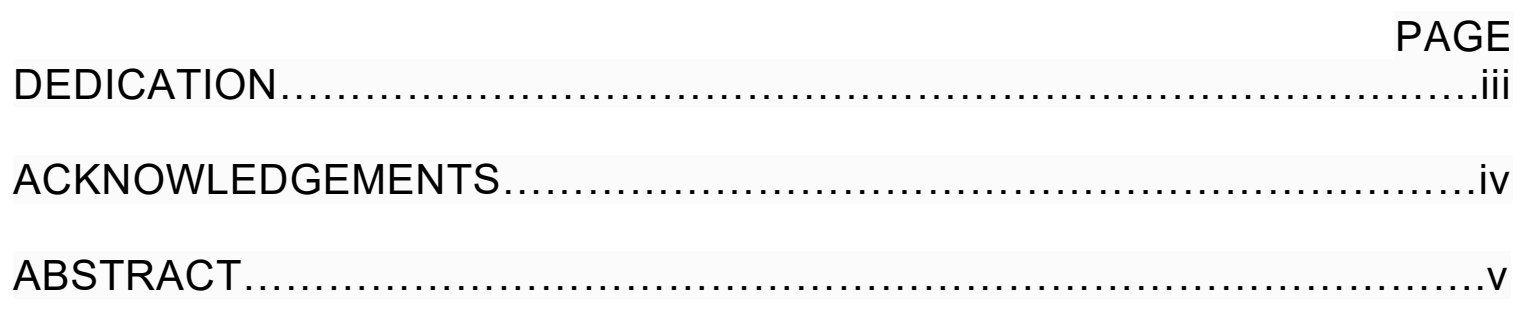

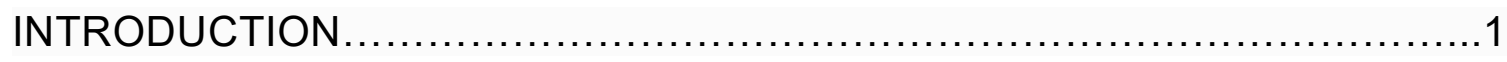

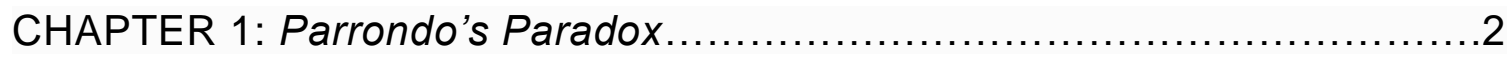

CHAPTER 2: Shadows of Patterns...................................... 17

CHAPTER 3: Security Typologies...................................... 24

CHAPTER 4: Sensitive Documents.................................. 30

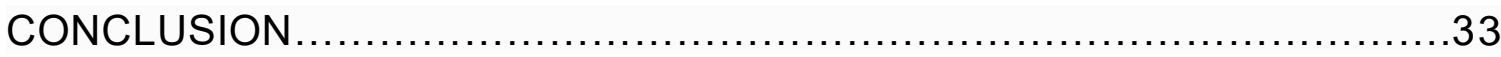

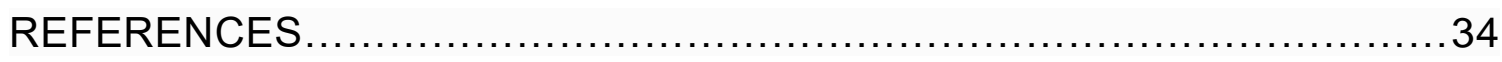

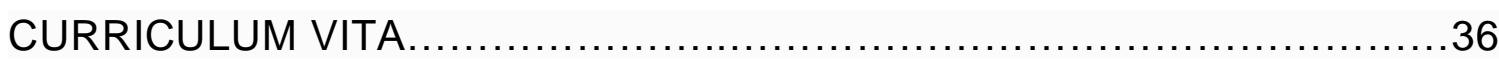




\section{INTRODUCTION}

In my home, as an adult raising children, I have experienced an irresolvable tension between creativity and reproductivity. This tension and it's following frustration has also been a theme I have heard articulated many times over in conversations with other mothers through my years of parenting. The work that comprises my thesis, Love Labors: Literal Symbols and True Abstractions, gives voice to this tension and by placing the work in the gallery, I hope to create the distance necessary to reflect upon it and consider why it exists. The domestic is often imagined and then pictured in advertisements, television shows and now Instagram, as a polished, cohesive, harmonious space that supports growth and relationships, but so often the images that we are most familiar with fall short of representing the more complicated and nuanced lived experience. All the pieces in this show, Shadows of Patterns, Security Typologies, Parrondo's Paradox and Sensitive Documents work together in articulating the lived experience of contemporary home life. 


\section{CHAPTER I}

\section{Parrondo's Paradox}

Random motion or "noise" in physical systems is usually considered to be a deleterious effect. However, the rapidly growing fields of stochastic resonance have brought the increasing realization that random motion can play a constructive role.

- G. P. Harmer and D. Abbott (1999)

Lay not up for yourselves treasures upon the earth where moth and rust doth corrupt....

-Matthew 6:19

At 3'x7', Parrondo's Paradox is a felted panel made from damaged garments that were at one time worn by various members of my family: my sisters, children, myself, my mother, my ex-husband, both naturally and artificially dyed wool roving, water, soap and friction. In the discipline of mathematical modeling, “Parrondo's paradox is a game theory by which a counterintuitive phenomenon can be observed in which individually-losing strategies can be played in combination to produce a winning expectation, discovered in 1996 by Juan Parrondo."1 I first encountered this idea listening to architect Keller Easterling give a lecture on her concept of medium design. The existence of the paradox and its potential to challenge the largely unchecked societally assumptions regarding the desirability of independence is what makes it useful to my purposes, driving the ideas behind the wet felted panel.

\footnotetext{
${ }^{1}$ https://www.nature.com/articles/srep04244
} 
"Parrondo's paradox is an example of how dependence can wreak havoc with probabilistic computations made under a naive assumption of independence." While my expertise lies far afield from mathematical modeling, game theory and the Brownian ratchet, the deep knowledge of which led to the discovery of this paradox, it is the application of this concept to the relationship between the lived experience, artmaking and existing aesthetic frameworks that I perceive to hold rich metaphoric potential. ${ }^{3} 4$ While the quote above applies to probability theory and underlying assumptions that lead to what kind of questions are asked and methodology used, we can translate the terms that are unfamiliar and specialized to lived experience through metaphor. Throughout our lives, it is typical to make calculations of how best to achieve our goals, these goals are rooted in certain expectations, largely predicated on how to best maximize our available resources; this process can be thought of as probabilistic computations.

This process is often thought of as an individual pursuit, disregarding the importance of our dependence on others and ignorant to the ways in which our lives intertwine with others. This ignorance can be thought of as naïve assumptions of independence that are then complicated by the reality of our dependence, for many, only apparent in adulthood when making family. This artwork, Parrondo's Paradox is a material embodiment of the consequent messiness and contingent organization that results from the coming together and pulling asunder action by which the lived experience of familial relations are

\footnotetext{
2 https://en.wikipedia.org/wiki/Parrondo\%27s_paradox

${ }^{3} \mathrm{https}$ ://plato.stanford.edu/entries/aesthetic-judgment/\#DisiLessAmbi

${ }^{4}$ https://royalsocietypublishing.org/doi/10.1098/rsos.171685
} 
defined. In other words, it is a physical manifestation of the principle that losing independence through interdependence by participating in a family-making, yields a "winning" outcome. The artwork is both physically substantial and precarious, both together and coming apart, becoming a literal symbol.

To arrive at the final state of Parrondo's Paradox, the various pieces that comprise the artwork went through many stages of being, adding to the content of the work. Additionally, wet felting is an unpredictable process of producing fabric, it is difficult to control and is labor intensive, the process largely dictating the outcome. But first, before that process began, I washed the garments in the washing machine in an attempt to eradicate the moth infestation. The washing and moth holes altered the garments and subsequently they were no longer wearable. I then deconstructed them, removing seams, buttons, etc., and in some cases the articles were dyed in natural dye to enhance the color, bringing the palette into greater harmony. From there I used common quilting tools: rotary cutter, a cutting mat and a clear quilter's ruler to cut the garments into right isosceles triangles.

The pattern that was then followed in reconfiguring the triangles and bringing them together into a single piece of fabric is from sourced from Ani Albers, Notebook 1970-1980. The drawings that comprise this book are ones that she made at the end of her life. Over her career she developed an extensive knowledge and maintained curiosity about pattern and cloth making, structure and design, then applied it all to an apparently simple but deceptively complex unit-the right isosceles triangle. By rotating the unit into its four possible 
positions and placing the units next to each other in a grid, randomly, or in a way so as to create an overall pattern, she utilized the inherent basis of all pattern making-repetition and variation-in making an array of arresting, engaging and endlessly variable designs. The play, mastery and inquisitiveness of an accomplished artist at the end of her life are on display in this humble publication. The metaphoric potential of this pattern and its origin are features that I am seeking to incorporate into my artwork and is the purpose behind the choice for this pattern.

The process of wet felting is known to all who have accidentally put a woolen garment into the washing machine. The water, temperature change and friction, all together, alters the fabric; drawing it together into a tighter configuration. Most of the time this process renders the garment unwearable. Wool is also a life sustaining material for moths, as the quote from Matthew at the beginning of this chapter reminds us, in metaphor, not to place our treasures upon the earth where the moths and other shadowy corruptors lie in wait. Wool is able to hold $30 \%$ of its weight in water before it feels wet to the touch-assisting this fascinating capacity of the material are the microscopic scales upon its surface. ${ }^{5}$ Those scales are what make it an ideal material for felting; the fibers catch and intertwine during their exposure to friction and moisture, they become caught upon one another and once together, become inseparably bound. The metaphoric significance of the process by which Parrondo's Paradox came into

\footnotetext{
${ }^{5}$ https://www.sciencelearn.org.nz/resources/875-wool-fibre-properties
} 
being is embedded into the content of the piece through the language of its origin and materiality.

Parrondo's Paradox is a visual representation of this process, its appearance of simultaneously becoming and falling apart speaks equally to the delicate wobbliness and an impure finish inherent to family-making and feltmaking. By using old garments, a pattern developed by an artist at the end of her underappreciated career (dying far less remembered than her husband Josef Albers), personally laboring over the piece by creating the friction necessary to unite the disparate parts, utilizing common household machines and tools in its realization, and then placing it in a gallery, I am offering an alternative to our current binary modes of thought as they relate to homemaking and artmaking.

This mode of thought regarding the opposition between homemaking and artmaking is perfectly articulated by Marina Abramovic in a 2016 interview with Guelda Voien for the Observer. The then 70-year-old art-star and arguably the world's most well-known performance artist reiterated her long held stance on artmaking and childrearing: "In my opinion [children are] the reason why women aren't as successful as men in the art world. There's plenty of talented women. Why do men take over the important positions? It's simple. Love, family, children—a woman doesn't want to sacrifice all of that."

In the spirit of architect Keller Easterling's recommendations regarding design possibilities that will offer us a way out of current cultural impasses such as this one, Paranodo's Paradox is attempting to offer an alternative to "the modern Enlightenment mind" of "closed loops and binary thinking" that places 
homemaking/childrearing and artmaking in opposition to one another. It is my goal with this work to bring love, family and children out of opposition to that which is required for a woman to be a successful artist and instead present a piece of artwork that is a literal symbol of, "pursuing a fascination with simple components that gain complexity by their relative position to each other." 6

While Easterling is speaking to design solutions on a larger scale as they relate to global warming, pandemics, structural racism, financial risk or technological failure, the most salient illustrations of her radical position reference parenting, playing pool and other everyday instances of: in the moment, on the ground, dynamic decision making, for which most people have a reference point. She urges a move away from the "(m)odernist scripts" that "fuel the binary fight." Her writing and insights into design call into question our inclination as a society "to reinforce "the one," bombastic arguments (that) must naturally ask for successive rather than coexistent thoughts or practices." Paranodo's Paradox by its existence, is perforce offering an alternative and can be thought of as a means of dislodging the dominant model of thinking about creativity born of teleologically truths that place artmaking and homemaking at odds.

The historical trend voiced by Abramovic that places creative work and love labor of the home and the work of artmaking is deeply entrenched. The frustrated relationship of women to the home and to society at large was explored in much of the first and second wave feminist artwork of the 1960's and

${ }^{6}$ Keller Easterling. Organization Space: Landscapes, Highways, and Houses in America. The MIT Press, 1999.

${ }^{7}$ Keller Easterling. Medium Design Knowing How to Work on the World. 
1970's. An example par excellence of this frustrated opposition is on display in Martha Rosler's 1975 experimental video/performance artwork, Semiotics of the Kitchen, in which Rosler labors through the alphabet, associating each letter with common and sometimes outdated kitchen utensils and objects while addressing the camera-all performed with a mock cooking show aesthetic.

While this work today feels clunky, given the multiplicity of women's roles in the labor market, I both see the issues that she addresses with the work as unresolved and I see my work possible because of it. By detaching the dominant, naturalized notions of "happy homemaker" and pointing, rather crudely, to the semantic system responsible for creating the relationship, deeper analysis and questioning of the woman's role in society and the home was made possible. The work did not however, offer any resolution to the question, who, if not the woman, will take out the trash, do the laundry, sweep the floor, nurse the baby, and enjoy this labor as essential and life sustaining?

Post-Partum Document (1973-1979) by Mary Kelly shares Rosler's analytic, cold and uncelebratory aesthetic, but rather than women's work in the kitchen, Post-Partum Document, interrogates mothering, using diagnostic tactics gained from University study. Both Rosler's and Kelly's artwork is theoretically underpinned by philosophical texts primarily written by men who had maids. In Post-Partum Document, Kelly deployed her skills and proved her study, evidenced in part by the dispassionate presentation of 139 individual pieces of familial data, her son's soiled diapers included. It is another seminal second wave feminist artwork to which I am indebted, but as with Rosler's video, it 
smacks of the emotional/corporeal distance required when content of this kind is put forth within the artworld context.

Kelly's work problematizes the limited and confining associations of motherhood with sentimentality by presenting "raw data" and offers with PostPartum Document an alternative, more complex view into the mother/child relationship, albeit on a mostly detached note. Both Rosler's Semiotics of the Kitchen and Post-Partum Document work to unpack the assumptions that naturally situate women in the kitchen and singularly define mothering as a sentimental act, respectively, by investigating how people and subjectivity come to be through language. But their works leave questions unanswered; who will lovingly cook the food, birth and care for children now that the woman is decoupled from the kitchen and has demonstrated understanding that language makes the person, not the mother?

During the 1970's while Rosler and Kelly were making their artwork, in America, women were rallying together through singing, writing, marching, burning their bras-challenging all aspects of the patriarchal definition of acceptable female labor and behavior. Women's artmaking practices at this time expressed/housed much of this dissention, though in the male dominated artworld those who were most established were reluctant to accept much of this work. ${ }^{8}$ The artwork's relevance and value were largely accepted or rejected based upon the grounds of who was making the work. The idea of women's intrinsic connection to the body, with child making, as object of male desire, etc.

\footnotetext{
8 Parker, Rozsika, and Griselda Pollock. Old Mistresses: Women, Art, and ldeology. 1St Americaned. New York: Pantheon Books, 1981.
} 
was so deeply entrenched, that much of the work that was made by women, regardless of the content, was often perceived as being in opposition to the dominant, acceptable mode of artmaking at the time-that which demanded cerebrally born acts of creation, exclusively.

Rosler's and Kelly's aforementioned work sufficiently met this criterion for success though was deeply criticized, especially in the case of Kelly. Many other women artists also became successful during this time despite directly and sometimes indirectly peering into and bearing witness to the problems of women, subjectivity, labor and the body with their artworks. Mierle Alderman Ukeles, with her performance work addressing sanitation, care, compensation and labor; Carolee Schneemann's exploded canvases that spoke to power, sexuality, violence and the female body; Judy Chicago with her artwork, The Dinner Party ('74-'79) that probed and exposed the prevailing wisdom of her day that minimized women's contributions to history and culture. These women artists gained access to the major museums and institutions of their day, mostly with their cerebral, corrective, counteractive art works.

Many other female artists working during this era of feminism's first and second wave were subject to a lack of critical interest and engagement, as well as general confusion in terms of how to categorize the work. Often the work made by women artists, and women textile artists in particular, were consigned to realm of decorative arts, the ultimate artworld dismissal of the day. Making artwork that was decorative, utilitarian or demonstrated deep technical prowess 
in the persistently Greenbergian dominated field of art criticism at this time ${ }^{9}$ was tantamount to being cast aside, and understood as unimportant and/or irrelevant. This conceptual/material divide in the acceptance/rejection of artworks was wrapped up in the theory of the day that was busy problematizing beauty and subjectivity, redefining the cannon.

The Avant Garde artworks of the day were most celebrated when they demonstrated experimentation, or innovation, or as direct manifestations of the theory being disseminated; minimalism, and then later installation art, happenings, performance art, pop art are all demonstrative of a time heady with post war change and capital, all in their own ways, challenging the status quo. The female artists who worked with textiles during this time, some of the most well-known being Ani Albers, Lenore Tawney, Sheila Hicks, were only marginally accepted..$^{10}$

This cocktail of new post war prosperity coupled with the increasingly expansive possibilities with regards to the question, "What is art?" required guidance from critics to navigate. Echoingly among those critics, intellectualism and application of theory in artwork was championed. Beauty, craft and good design were only tools to be wielded in service of the ongoing cerebral, modernist interrogations of space, time, subjectivity, consciousness, et al. And a precondition for acceptance into the artworld was that the work be situated within the existing theoretical frameworks touted by the critics at the time. Further, in

\footnotetext{
${ }^{9}$ Auther, Elissa. String, Felt, Thread: The Hierarchy of Art and Craft in American Art. Minneapolis: University of Minnesota Press, 2010.

${ }^{10}$ Auther, Elissa. String, Felt, Thread: The Hierarchy of Art and Craft in American Art. Minneapolis: University of Minnesota Press, 2010.
} 
order for the work to be considered as anything other than decorative, i.e. irrelevant, it must also operate within the general understanding that a precondition for an aesthetic experience with a work of art must be a disinterested one, a persistent ideological contribution to our modern conception of artwork inherited from the writings of Immanuel Kant.

This prevailing aesthetic mode of inquiry also purports that there is a hierarchy of the senses that have then dictated whether areas of epistemological inquiry are legitimate or illegitimate. This aesthetic hierarchy places sight and hearing senses above touch, smell and taste and is inherited from the beginning of western philosophy as espoused by the likes of Plato and Aristotle, and then later reaffirmed by early psychologists of the $20^{\text {th }}$ century. ${ }^{11}$ This hierarchy has also strongly informed contemporary scholarship, art practices and criticism, scientific research and lived experience alike, and is reflected in our semantic system that is currently bereft of vocabulary necessary to parse the cacophonous, lived experiences of touch, smell and taste. ${ }^{12}$ Locating and unpacking the specific ways in which the traditional aesthetic hierarchy of the senses and requirement of disinterestedness in relation to the aesthetic object has impacted women's artmaking practices, inclusive of chosen subject matter, presentation, location and critical reception feels like an essential task given the proximity of women and the corporeal.

\footnotetext{
${ }^{11}$ https://www.nytimes.com/2021/01/28/magazine/covid-smell-science.html

12 https://www.nytimes.com/2021/01/28/magazine/covid-smell-science.html
} 
By questioning these statutes with new artworks and theory, we can turn the dial away from the tired out, limited, and unsustainable narrative heard on the Abromovic station. Fleshing out the conflict through artworks that defy the logic required to maintain these ideologies, we can observe that the prevailing adherence to sense hierarchy, coupled with Kant's assertion that a precondition for authentic aesthetic experience necessitates the audience view the work from a disinterested vantage point are far more deserving of an indictment in their causal relationship toward women's lack of success in the artworld than Abromovic's claim that familial relationships, inclusive of love and personal entanglement, are to blame.

Within the framework that excludes certain bodily systems and only permits sterile aesthetic exchange, much of the lived experience has been disallowed from offering valuable contributions to knowledge acquisition, thus historically, making the phenomena of the everyday off limits to deep and serious inquiry in philosophy as well as art making. The prevailing wisdom inherited from these modes of thought and attitude toward the senses combined, are also at work in maintaining distance between artmaking and homemaking by opposing the body and mind.

Of course, the binary opposition between body and mind is inherited from the Greeks and was incorporated into the foundation of early Christian and later Puritan theology that has subsequently permeated western culture and thought. But here, with my artwork and writing, I wish to shift away from the "binary loop" and sluff off the "modernist Enlightenment thinking" that perpetuates this myth of 
opposition by exposing the limitations of these ideologies, and properly identify this as a main contributor to the paucity of work made by women concerning the home, childbearing, and childrearing within the scope of serious work.

Often driving the work that does get made are these held ideologies that blockade mothering/homemaking from entering the dialogue. Modern scientific research operates similarly, disincentivizing certain areas of research because it does not fit with what is currently understood to be significant. This practice prevents expansion of knowledge and has limited what kind of work gets made. Keller Easterling stated in the introduction to her 1999 Publication, Organization Space: Landscapes, Highways, and Houses in America, "We are most comfortable with nouns rather than verbs, with artistic products that have representational currency, and with organizations that can be optimized."13

With Paranodo's Paradox, I aim to sublimate these limited modes of inquiry that have been imposed upon knowledge acquisition and artmaking practices. Both Rita Felski's and Yuriko Saito's scholarship in the field of Everyday Aesthetics has assisted me in this pursuit by widening the traditional scope of aesthetic inquiry. These contemporary philosophers not only challenge the intellectual traditions that place senses in a hierarchy, but they have also turned their attention to the aesthetics of commonly shared, mundane experiences that populate most people's everyday lives, inclusive of

\footnotetext{
${ }^{13}$ Keller Easterling. Organization Space: Landscapes, Highways, and Houses in America. The MIT Press, 1999.
} 
maintenance activities such as washing, eating, folding laundry, interactions with the natural world, and spending time with children. ${ }^{14}$

Their scholarship problematizes Kantian dictates, and works to close the gap between the lived experience and intellectual inquiry through their admission of the everyday as a worthwhile aesthetic concern. It has opened the space that allows for the possibility of everyday phenomena having metaphysical potential, thereby releasing the mind and body from being held in opposition. By utilizing everyday knowledge with household materials and tools in the construction of Paranodo's Paradox, inviting engagement with its messy but orchestrated appearance, evoking the sense of touch and the body through its tactility, it's obvious construction from worn garments, and by presenting the work in the rarefied space of the gallery as art, I too hope to close the gap.

Paranodo's Paradox, is an entangled representation of lived familial life and owes gratitude to the works of the early feminist artists, but with this work, I am seeking to incorporate rather than distance the work from the feminine body, its generative possibilities and cultural/historical proximity to the mundane and to beauty. This work is an act of celebration, and rather than justify the work by situating it within the male dominated context of epistemological knowledge acquisition as my forbearers have done, rather, I wish the work to appeal to the lived, everyday, haptic experience, working to reinforce and reaffirm this knowledge. I wish this piece to be an artifact of care that bears witness to the precarity and strength to be found in the interdependence of the family, a

\footnotetext{
${ }^{14}$ Saito, Yuriko. Everyday Aesthetics. Oxford: Oxford University Press, 2007.
} 
beautiful articulation of "components that gain complexity by their relative position to each other". 


\section{CHAPTER 2}

\section{Shadows of Patterns}

Shadows of Patterns is a series of twelve cyanotype images of scanned, in-process or damaged, hand-knit garments-my own and also projects given to me by fellow knitters. These images represent suspended intention, this suspension articulated by their blue color. Rendered in cyanotype and presented as a group, the images speak collectively to the concept of the color blue explored in Rebecca Solnit's, Field Guide to Getting Lost. In this volume of contemporary, creative nonfiction, she poetically describes the color as that which you cannot hold. She states: "blue is the color that represents the spirit, the sky, and water, the immaterial and the remote, so that however tactile and close-up it is, it is always about distance and disembodiment." Though this photographic process affords deeply detailed images and fidelity to the objects that it represents-having been used in the create architect's blue prints and botanical reference books alike-the blue of the cyanotype here allows for the distance required to contemplate what the unfinished objects could represent: suspended intention, and all that prevented the work from being completed.

The knitting is first scanned and therefore becomes digitized, the objects go from being loops of yarn, looped into other loops in the knitting process to then becoming flat pixels. From there, I alter the image in Photoshop, by 
increasing the amount of values in order to enhance the texture of the material so as to command presence on the page once they become monochromatic. Once the image is optimized for this purpose, a digital negative is printed using an ink jet printer, from there, the images of the knitted goods leave the digital realm. The rag paper is coated with a thin layer of cyanotype chemistry and left to dry. Due to the reaction of the chemistry, the coated paper is light sensitive, with the negative on top, it is then exposed to light, creating a print of the image. Patterns of shadows result.

Shadows of Patterns are detailed renderings of hand-knitted goods and through the vehicle of metaphor described by Solnit, the shades of blue level the objects' specificity and creates space for contemplation. Contemplation toward that which leaves the objects undone yet still around. In my early years of mothering, while I would knit on the bus, or in other public places, women would often stop and chat, relating it to their own life experiences. "Forty years ago, my mother started a sweater for me that is still unfinished, its sitting in a box somewhere at my house." Another anecdote, "When my boy was first born, I knit an entire blanket but haven't completed anything since." I have found through time in the practice myself, and after having heard many stories such as these, that it is often the case that hand knitting is left for long periods of time before it is picked back up again, if ever. People keep the projects around for eventual completion, to repurpose the yarn, or to the keep the knitting as a relic of a past ambition to create something. All are significant but it is this last impulse that is of greatest interest to me. 
Handicraft of any kind, at this point in western culture, is an optional endeavor mostly taken up in people's leisure time. Though knitting's negative association with thrifty grandmothers is not entirely absent, in recent years knitting has been redefined, holding currency in the D.I.Y. trend, Etsy culture, and also high-end, handmade goods. Hand knitters have a sizable presence on the internet, there are YouTube tutorials on how to do any and all possible stitches, bespoke patterns and yarns are featured and sold in splashy Instagram feeds, as well as a staggeringly information rich social media platform called Ravelry through which millions of subscribers from across the world are connected. That knitting has persisted in enticing new engagement in our contemporary culture of fast fashion and that it has gained particular traction with younger people who have been acculturated in the digital era, both, are testaments to the activity's vitality.

Despite this vitality, our modern attention economy can be inhospitable to the process' plodding pace. Knitting is methodical; by careful, slow, deliberate action one strand of yarn can become a garment, blanket or adornment. Another distinctive feature of the medium is that the subsequently made garment will carry traces of many stages of decision making made well before the yarn is in the knitter's hands. The unique characteristics of each kind of raw fiber: silk, cotton, linen, wool, the organization of those fibers, the twist and/or ply in which the fibers were spun-all will impact the quality of the garment, as much as the tension the knitter carries as she handles the yarn while knitting. 
Deep knowledge of the material is not required to be a successful knitter, though the intimacy created from the amount of time put into making a finished piece does lead many to devote themselves to learning more. I hypothesize that acquiring this deep knowledge can lead to a greater respect and appreciation for those materials, and that the relationship developed through time spent with the object underlie why many knitters keep an unfinished object around long after, for example, the child has outgrown what it might have become. But what leads the knitter to pick up this precious material and endeavor to make a thing for herself or for a loved one, how the skill was acquired and why it persists in being a love language despite the activity no longer being necessary in our commodity culture, is the shadowy place that I wish to open up for contemplation by making cyanotype images of these unfinished garments.

Elizabeth Barber in her book, Women's Work the First 20,000 Years, locates childrearing as the deciding factor that informed the division of life sustaining labor in prehistoric societies. She pragmatically identifies the activities of cloth making and food preparation as forms of labor that do not conflict with caring for and tending to the needs of the vulnerable, i.e., growing children who need to remain close to their food source, their mothers. Additionally, the added benefit of this proximity early in life led to training those children to be a valuable source of labor in these life sustaining activities. Modernity and its attendant conveniences do not require this organization of labor, but yet the need for care remains. 
As any parent or individual who has tended to an elderly parent, or disabled family member knows from experience, caring for the vulnerable can create a barrier to success outside of the home for all who must perform it. Many contemporary scholars are turning their attention to this limitation and identify the main contributor to this problem as being the way in which we define "productivity" in modern society. In a 2019 speech, Marilyn Waring, a publicpolicy scholar, pointed to the ways in which care of this kind were largely identified as leisure activities, not labor, and as such had no value. In this speech she states, "You cannot make good policy if the single largest sector of your nation's economy is not visible,"

The cyanotypes in Shadows of Patterns are the blueprints of the labor and care required to make these objects, the impulse from which they arise, and all the tasks (requirements of modern society) which prevented their completion or mending. With this work I seek to expose this relationship and make this "invisible labor" and its incompatibility with our contemporary cultural constructs as they relate to care, visible. If language is particularly good at giving us glimpses into the past as linguist and archeologist, Elizabeth Barber asserts in her aforementioned book, then the lack of words/language around these labor/care activities in our contemporary lexicon is revelatory. To this point, Andrea Komlosy's scholarship in which she parses the historical/semantic difference between labor and work in English (and Arbeit and Werk in German) in her book, Work the Last 1000 Years, demonstrates that we simply lack the vocabulary to adequately identify the value of work activities that do not conform 
to the capitalistic definition that has so completely usurped the multitude of Greek and Latin words that enabled a more nuanced semantic understanding of the activity we now just call work.

Presenting these projects in this format, as a taxonomic record, is a move that I hope expands the current narrative that identifies these objects solely as undone or unproductive. I wish for these images to allow the space for the objects represented to speak as acts of resistance to "a social system committed to the devaluation of our lives," ${ }^{15}$ as feminist activist and writer Silvia Federici argues our current capitalist model operates in accordance with. I hope that Shadows of Patterns can work as a means of restoring that value by offering them as representations of the value of care and simultaneously of the crushing system that flattens our experience of it. "Federici is a longtime advocate of the idea that domestic work is unwaged labor... and it is a form of gendered economic oppression, she argues, and an exploitation upon which all of capitalism rests." 16

My impulse is driven by the need to mark, categorize and present this mostly unseen/undescribed form of care. Collected, scanned, and then printed as a group in cyanotypes, collectively, they amplify these otherwise individual

\footnotetext{
${ }^{15} \mathrm{https}: / /$ www.nytimes.com/2021/02/17/magazine/wagedhousework.html?campaign_id=52\&emc=edit_ma_20210219\&instance_id=27258\&nl=the-newyork-timesmagazine\&regi_id=143779994\&segment_id=51954\&te=1\&user_id=db9edeb55d59d62ac2a5b35 d75f24b2e

${ }^{16}$ https://www.nytimes.com/2021/02/17/magazine/wagedhousework.html?campaign_id=52\&emc=edit_ma_20210219\&instance_id=27258\&nl=the-newyork-timesmagazine\&regi_id=143779994\&segment_id=51954\&te=1\&user_id=db9edeb55d59d62ac2a5b35 d75f24b2e
} 
testaments to the creativity required of the knitting process and to that which is required in interpersonal relationships. The images represent small actions which resist societal pressure toward the commodification of care. By transforming them into two-dimensional images, hung in a gallery, they can become sites of contemplation rather than only as shadowy reminders of tasks left undone. In the gallery, these individual testaments of care are presented as precious objects, labored over to reveal their preciousness to a more general audience, not requiring of specialized knowledge to appreciate. I would like for them to speak to and also beyond the craft of knitting; to succeed in pointing to cultural currents that inform our everyday-to the tension that exists between care and capitalism.

Lucy Lippard wrote extensively about the Minimalist artists of the 1960's:

Sol LeWitt, Tony Smith and Robert Morris, among others. In her 1983 publication, Overlay, she describes the minimalist project as that which was pursuing a more collective base "in reaction to the decades of existential emphasis on the individual through new non-representational content"17. Lippard identifies these artists as seeking to communicate through universal systems of non-representational content, I see Shadows of Patterns as carrying on that mantle, by acting as a site of representation that simultaneously points to the macro cultural factors underwritten by capitalism that work to delegitimize the value of care and to our capacity to resist them through engaging in meaningful acts of care.

\footnotetext{
${ }^{17}$ Lippard, Lucy R, and Pantheon Books. Overlay: Contemporary Art and the Art of Prehistory.
} Firsted. New York: Pantheon Books, 1983. 


\section{CHAPTER III}

\section{Security Typology}

Global financial systems that impact us all are complex, multifaceted entities that we can really only conceive of abstractly, this is primarily accomplished by flattening them into digestible, measurable data such as individual credit scores and debt to income ratios. Security Typologies is a representation of how these abstract concepts enter our homes and the way in which the presentation of these systems by financial institution operates to obscure the gravity of engagement with those institutions. With this work, I am seeking to emphasize the gamed, benign way in which these complex systems are presented to us by translating this at-one-time trash into a grid of images that upon first glance have a sensual, approachable appearance, made possible by their materiality.

Arranging these similar but different images of opened envelopes into a grid format speaks to the constrictive financial systems that force us to negotiate away our time and think of it, too, as an abstract concept. I hope to also visually articulate the limitations that exist in the choices we have available to us. The limitations of differentiating ourselves through our purchase at big box stores such as IKEA and the like. Speaking to time and IKEA in turns, Eula Biss, in her 2020 book of creative non-fiction, Having and Being Had, speaks to her greatest 
desire, having time and the deficit of desirable furniture with which to furnish her home. The old adage, Time is Money is so thoroughly embedded into our conception of it that our time is no longer experienced as the unalienable resource that it is.

With Security Typologies I am utilizing the presentation strategy made popular by artist team, Bernd and Hilla Becher in the 1960's with their various series of "typologies". Their photographs of industrial buildings and structures were presented in a grid of similar but differentiated objects from dying industries, taken in post war Wales and South England. As the Becher's eliminated distinguishing elemental features, i.e. atmosphere, light and the presence of people in their photographs, I have scanned each envelope and adjusted the exposure of the scans to enable a comparison of the formal features of the images of envelopes to take place, working to abstract the objects. As Bernd Becher, I too have studied typography and seek to exploit the potential of presenting these images as cyphers, understanding that through that translation comes the capacity to read the images symbolically allowing them to then be deciphered. Presented in a grid, a syntactical understanding of both the buildings and envelopes becomes possible, allowing the nuanced differences and commonalities to become visible and potentially read.

By spending time deciphering this grid of seemingly innocuous, similar, but differentiated, colorful images in Security Typology, we can suddenly arrive at a sense of collective dread while we discover the source of these images. Thinking of the moment these envelopes become trash after performing their role 
in making the documents contained within unreadable, obscuring the sensitive financial information that they contain, for our "security". Perhaps through this presentation, the act of opening these envelopes and discarding the documents that they contain regarding our credit standing, bank statements, and offers to sell our debts to another institution is invoked. I have been collecting a seemingly endless stream of these envelopes for the three years while in Graduate School and they contain a seemingly never-ceasing lure to transfer a balance, reduce my rate, or enlist another such service to alleviate or offer gain by aligning myself with their institution. The documents contained within these envelopes make it clear that they will, for a short time, offer a smaller percentage by which to pay them back your debt.

Security Typology is a series of 16 (16"x $\left.16^{\prime \prime}\right)$ single layer, silk screen images derived from scans of opened security envelopes. The images are translated into a halftone in photoshop and were then screen printed in a variety of colored dyes on silk Habotai panels, stretched around square wooden stretcher bars that have a 2" depth. After the envelopes were made into digital images and then printed as a negative onto transparency material that were then exposed to an emulsion-coated silk screen. When printed upon the silk, the dye permanently, chemically affixes the image to the cloth. By using silk and brightly colored synthetic dyes, I am speaking to lux surfaces and their attendant haptic associations. References to silk are rife in advertising to women- silky smooth legs, hair as fine as silk; it is and has been a fabric associated with luxury. 
I translated the image of the scanned envelope into a halftone as a means of preserving the photographic artifacts found in the original scan (i.e. dropped shadow, ripped paper surface) that assist the viewer in locating what these images represent. The halftone also works as a reference to the ways in which images have been reproduced in print and is a visual language used by many artists before me such as Roy Lichtenstein and Andy Warhol in speaking about the proliferation of sameness in mass culture through the reproduction of images.

The goal of this work is to take these potent yet discarded items from the home that are already patterned to create a new "pattern". From a distance, it is difficult to discern what the images are, but by being placed within a grid, the viewer can slowly, through comparison of the individual parts, locate the objects that these images represent. These envelope images point to global financial systems, the operations of which begin with decisions made by individuals, those decisions then impacting other individuals. The particularities of what these envelopes once contained is not revealed, they could be as innocuous as an offer to move debt to get a better interest rate, or as consequential as a foreclosure notice.

These documents that were once contained in these envelopes point to the ways in which sets of constraints that are dictated by immovable circumstances, children, the cost of education, real estate, etc. that inform people's choices can become somewhat predictable and then quantifiable as data points by these financial institutions; it is a contemporary means of being known or assessed. Both the financial collapse of 2007/2008 and the Covid 19 
pandemic have brought these realities of the domestic space into the national news, thus exposing through mass communication the commonalities of the lived experience in crisis. These news reports about domestic life, people overspending, overextending, using their assets to borrow against, have been further analyzed; the data gleaned from such analysis has been used to make even more irresistible financial products, and emphasize the need for mass inoculation.

I hope the viewer's encounter of Security Typologies can create a space for contemplation of the heady reality of living in the wealthiest-country-in-theworld-of-all-time. Underpinned by these financial systems, this country offers to its citizens ample "free" time to spend and so many things to buy on Amazon. The spending habits of people in this country are now understood as a global current, affecting the world at large. This grid of images that represent open envelopes act as a symbol of the interaction between these financial systems and the individual. The envelopes having arrived in the home containing documents of the individual's position within that system.

By utilizing the language of colorful, approachable, gridded sameness, familiar to all who participate with online banking and financial apps, I am hopeful that Security Typology points to these ubiquitous systems. The interaction with which oppressively flattens existence into financial standing. The work simultaneously appeals to the viewer's sensual proclivities through its materiality, and their intellectual capacity to recognize patterns. The hope being that encountering the work will then lead to a synthesis of that data into the 
development of new ideas. With this work I am striving to spark a feeling of enjoyment in the encounter that then leads to disillusionment with the way in which the self is so heavily informed by entanglement with financial institutions. I wish for the tension between the form and content of the work to articulate the tension between the construction of the self through financial data, credit scores, et al, and experience that is bodily, lived and irreducibly haptic. 


\section{CHAPTER IV}

\section{Sensitive Documents}

With the Sensitive Document series, I am working upon the premise that the home can be thought of as metaphor for our own interior. This concept has prompted the presentation of this home detritus as a series of single but heavily layered images. I scanned and then combined drawings, notes, bills, envelopes, origami, etc. made by myself and my family members in Photoshop. This presentation of layering disparate visual information into a single image is an attempt at visually representing the lived experience of home life. Working with the metaphor of the home as interior becomes complicated when the individual is responsible for caring for and organizing the detritus of others as well as her own. This complication is rendered in the chaos of this series of images.

These images are the visual representation of the ways in which these sensitive documents pile up in a non-hierarchical way regardless of their content. This ephemera is labored over and digitized as a means of preservation but also as a means to visually articulate this feeling. Utilizing digital technology to render analogue objects together, as though they are of an inseparable piece, also speaks to the ceaseless deluge of visual content made possible by digital technology and connectivity. The chaotic presentation also works as a critique to the dominant online sharing culture that requires all moments, especially the domestic ones, to be distilled into perfectly-lit vignettes of 
prosperity/happiness/polish to prove to yourself and others that your student loans and mortgages are worth it.

The requisite curation of the domestic setting found in Instagram Feeds is similar to the maintenance and the illusion of ease that can be seen in the manicured lawns of suburbia. Yuriko Saito in her book Everyday Aesthetics, describes an aesthetic reckoning guided by the green aesthetic sensibility that allows us to "modify our initial attraction with a sense of "disillusionment" created by the discrepancy between the seemingly beautiful appearance and its harmful content." ${ }^{18}$ As with the effort required in lawn maintenance, I see the effort that is required to maintain a perfectly curated Instagram feed of the domestic space as harmful. Lawncare excessively and unnecessarily pollutes the natural environment, what is required to preserve and maintain the monoculture is at odds with nature.

The curated Instagram feed and its relentless contrivances of clean, harmonious family life and the uniformity of domestic space that houses it, pollutes our interiors with unrealistic images of the lived experience. The presentation of curated images as impromptu and spontaneous instead of carefully, purposefully composed is an unsustainable endeavor, as unsustainable as a perfectly manicured lawn. Instagram user's adherence to and proliferation of the established advertising aesthetic works to further entrench this aesthetic as normative. This relentless picturization of family life works to further alienate people from their lived experiences that do not fit into this aesthetic, thus working

18 Saito, Yuriko. Everyday Aesthetics. Oxford: Oxford University Press, 2007. p85 
to alienate them from themselves. I offer Sensitive Documents as a means of reckoning with this harmful aesthetic impulse that requires sublimation of visual and actual messiness to the pictorial narrative of perpetual harmony.

Sensitive Documents are the anti-scrap book and I hope that while chaotic, upon further examination, the images are able to reveal beautifully poignant glimpses into the lived domestic environment. The disorder represented in the Sensitive Documents is familiar to most, and it is my aim that by creating this work the treacherous nature of the Instagram platform be laid bare, identified as harmful content. Revealing that the onus of failure is upon the proposition itself, not the individuals who fail to live up to this aesthetic. Perhaps with this artwork the audience can identify the personal/emotional debt that is incurred by engaging in the Instagram presentations of the everyday.

It is my hope that while personal to me, Sensitive Documents could work as a reminder for the viewers of their own metaphorical piles of household detritus, and can recognize that the forceful demand to present a polished image of home can work to co-opt the lived experience; that engagement with social media platforms can even result in alienation from the personal experience of the home. My aim with this work is to create sites of contemplation by elevating the discarded accumulations of my household into this realm, and by doing so affirm the beautiful mess of the interpersonal lived experience of the home. 


\section{CONCLUSION}

As a mother, partner and an artist, the roles I play/have played and their attendant expectations are often competing for my attention and time, not existing in harmony; my home is often not a place of respite but of demand. Demanding that I organize, care for, tend to and manage not only the items within, but the feelings that exist there; coexisting alongside my jumbled metaphoric and actual interior. The tender melancholy of the Patterns of Shadows, the accumulated chaos of the Sensitive Documents, the precarity of Parrando's Paradox and the taxonomic aesthetic of Security Typology all work together to give expression to the significance of caregiving, as well as articulate the simultaneous feelings of belonging and estrangement of modern home life. 


\section{REFERENCES:}

Albers, Anni, Ann Coxon, Briony Fer, Maria Müller-Schareck, Magdalena Droste, T'ai L. Smith, María Minera, Brenda Danilowitz, Jennifer Reynolds-Kaye, Priyesh Mistry, and Nicholas F. Weber. Anni Albers, 2018.

Albers, Anni, and Brenda Danilowitz. Anni Albers: Selected Writings on Design. Hanover: University Press of New England, 2000. Internet resource.

Auther, Elissa. String, Felt, Thread: The Hierarchy of Art and Craft in American Art. Minneapolis: University of Minnesota Press, 2010.

Bachelard, Gaston, Mark Z Danielewski, and Richard Kearney. The Poetics of Space. Translated by M Jolas. Newed. Penguin Classics. New York, New York: Penguin Books, 2014.

Barber, E. J. W. Women's Work: The First 20,000 Years: Women, Cloth, and Society in Early Times. 1st ed. New York: Norton, 1994.

Barthes, Roland. Mythologies. Edited by Annette Lavers, Hill and Wang, 1972.

Biss, Eula. Having and Being Had. Riverhead Books, 2020.

Chimero, Frank. The Shape of Design. First ed., Frank Chimero, 2015.

Easterling, Keller. Organization Space: Landscapes, Highways, and Houses in America. The MIT Press, 1999. EBSCOhost, search.ebscohost.com/login. aspx ?direct=true \&db=nlebk\&AN=138641\&site=ehost-live.

Felski, Rita. "Everyday Aesthetics" 2009, no. 71-72 (2009): 171-79. https://doi.org/10.1215/00265667-2009-71-72-171.

Fernie, Eric. Art History and its Methods: A Critical Anthology. London: Phaidon Press Ltd., 1995.

Irvin, Sherri. "The Pervasiveness of the Aesthetic in Ordinary Experience." The British Journal of Aesthetics 48, no. 1 (2008): 29-44.

Lippard, Lucy R. Get the Message?: A Decade of Art for Social Change. First ed., E.P. Dutton, 1984.

Lippard, Lucy R, and Pantheon Books. Overlay: Contemporary Art and the Art of Prehistory. Firsted. New York: Pantheon Books, 1983.

Lippard, Lucy R. Undermining: A Wild Ride in Words and Images through Land Use Politics in the Changing West. New York: New Press, 2014.

Harmer, G. P., and D. Abbott. Parrondo's Paradox. Statistical Science 1999, Vol. 14, No. 2, 206-213. 
Kelly, Mary. Imaging Desire. MIT Press, 1996.

Komlosy, Andrea. Work: The Last 1,000 Years. Translated by Jacob K Watson and Loren Balhorn. London: Verso, 2018.

McCracken, Janet. Taste and the Household: The Domestic Aesthetic and Moral Reasoning. Albany: State University of New York Press, 2001.

Parker, Rozsika, and Griselda Pollock. Old Mistresses: Women, Art, and Ideology. $1^{\text {St }}$ Americaned. New York: Pantheon Books, 1981.

Saito, Yuriko. Aesthetics of the Familiar: Everyday Life and World-Making. Firsted. Oxford, United Kingdom: Oxford University Press, 2019.

Saito, Yuriko. Everyday Aesthetics. Oxford: Oxford University Press, 2007.

Tanizaki, Jun'ichirō. In Praise of Shadows. New Haven, Conn.: Leete's Island Books, 1977.

Willink, Roseann Sandoval, and Paul G Zolbrod. Weaving a World: Textiles and the Navajo Way of Seeing. Santa Fe: University of New Mexico Press, 1996.

Woolf, Virginia, and Mary Gordon. A Room of One's Own. First Harvest edition 1989 ed., Harcourt, Inc, 1989. 


\section{CURRICULUM VITA}

NAME:

ADDRESS:

DOB:

EDUCATION

\& TRAINING:
Karen Weeks

1720 Gresham Road

Louisville, Kentucky 40205

Louisville, Kentucky - May 6, 1980

B.F.A., Printmaking

Indiana University, Bloomington

1998-2003, 2006

Scuola Internazionale di Grafica, Printmaking

Venice, Italy

2001 